\title{
Radiological Parameters for Conservative Management of Solid Organ Injuries in a Tertiary Care Hospital
}

\author{
Hridhay.K.Prit \\ Final Year MBBS \\ Saveetha Medical College and Hospital \\ Chennai, India
}

\author{
Dr. Perumal Boney \\ Department Of Surgery \\ Saveetha Medical College and Hospital \\ Chennai, India
}

Abstract:-

\section{$>$ Background and Aim:}

The management of solid organ injuries has changed drastically over the past couple of decades, with there being a shift from operative to conservative mode of management. The main purpose of this study is to establish radiological parameters for conservative management in order to make conservative mode of management more efficient.

\section{Materials and Methods:}

Retrospective analysis of solid organ injuries was done for 50 patients between January 2020 and March 2020 in a tertiary care hospital.

\section{$>$ Results:}

It is found that conservative mode of management can be considered for patients belonging to grade I, II and III according to AAST classification of Splenic and Hepatic injuries whereas in Renal injuries it is considered for patients belonging to grade I and II.

Keywords:- Radiological Parameters, Solid Organ Injuries, Hepatic Injuries, Splenic Injuries, Renal Injuries.

\section{INTRODUCTION}

Solid organs such as liver, spleen, pancreas and kidney are organs which are susceptible to tear or laceration by trauma to the abdomen, back or flank regions and can cause extensive bleeding. Solid organ injuries can be managed surgically or non- operatively. Non- operative management is referred to as the conservative mode of management.[1][2][3]

For management of solid organ injuries, there has been a huge shift in imaging algorithms as there is greater emphasis in detection of specific findings. These specific findings can tell us if there is a need for surgical intervention or if the patient can be managed conservatively. [4] Thus, it is of utmost importance to set specific radiological parameters to determine whether a patient is to be managed conservatively or if the patient requires surgical mode of management.
The most commonly used investigations include Ultrasound Abdomen and a Computed Tomography of the abdomen and pelvis. Based on these, the patients are classified according to American Association for the Surgery of Trauma (AAST) classification system and the radiological parameters for conservative management are thus determined. [5][6][7][8][9][10][11]

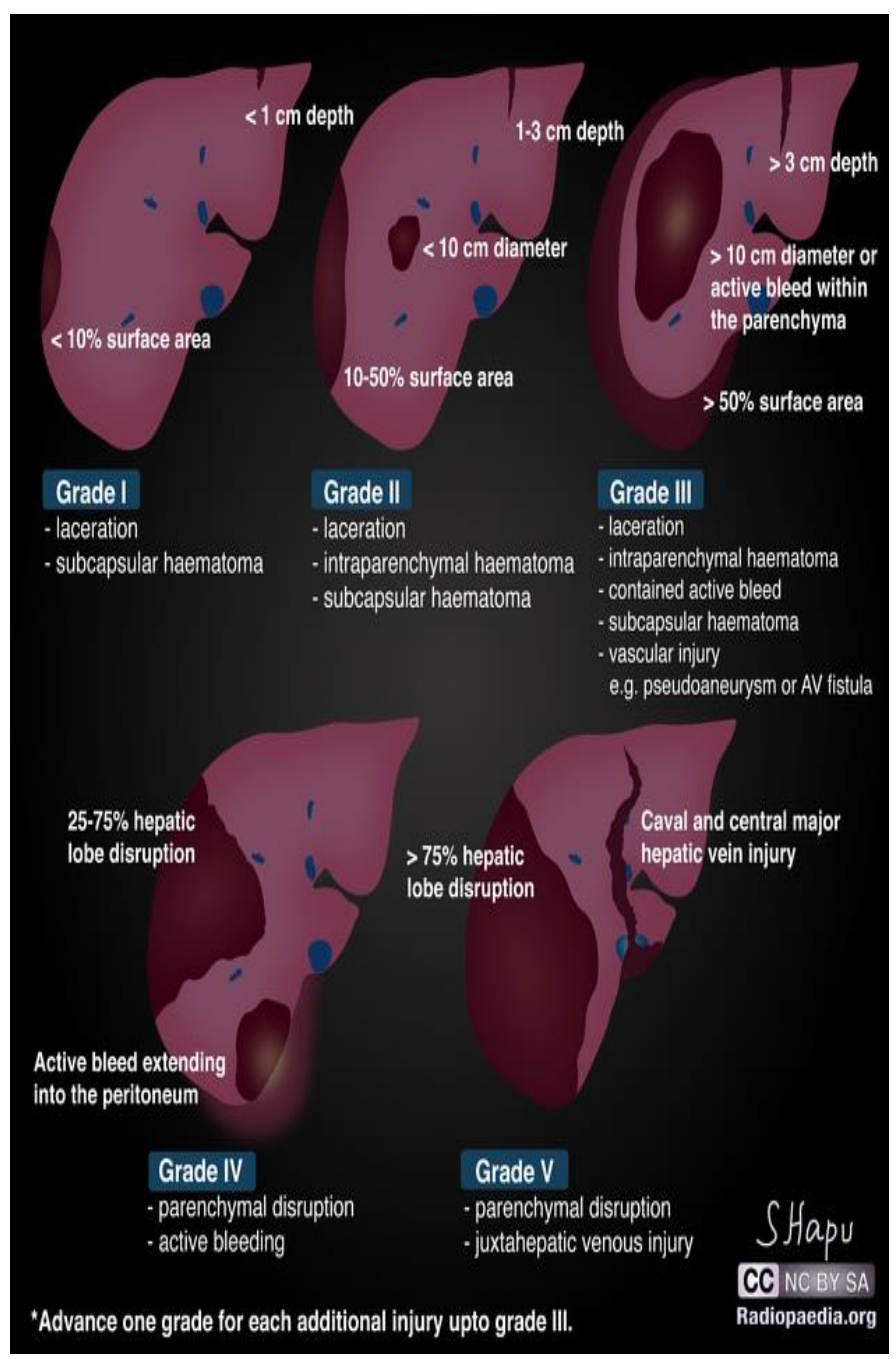

Diagram 1: Grading of Hepatic injuries 


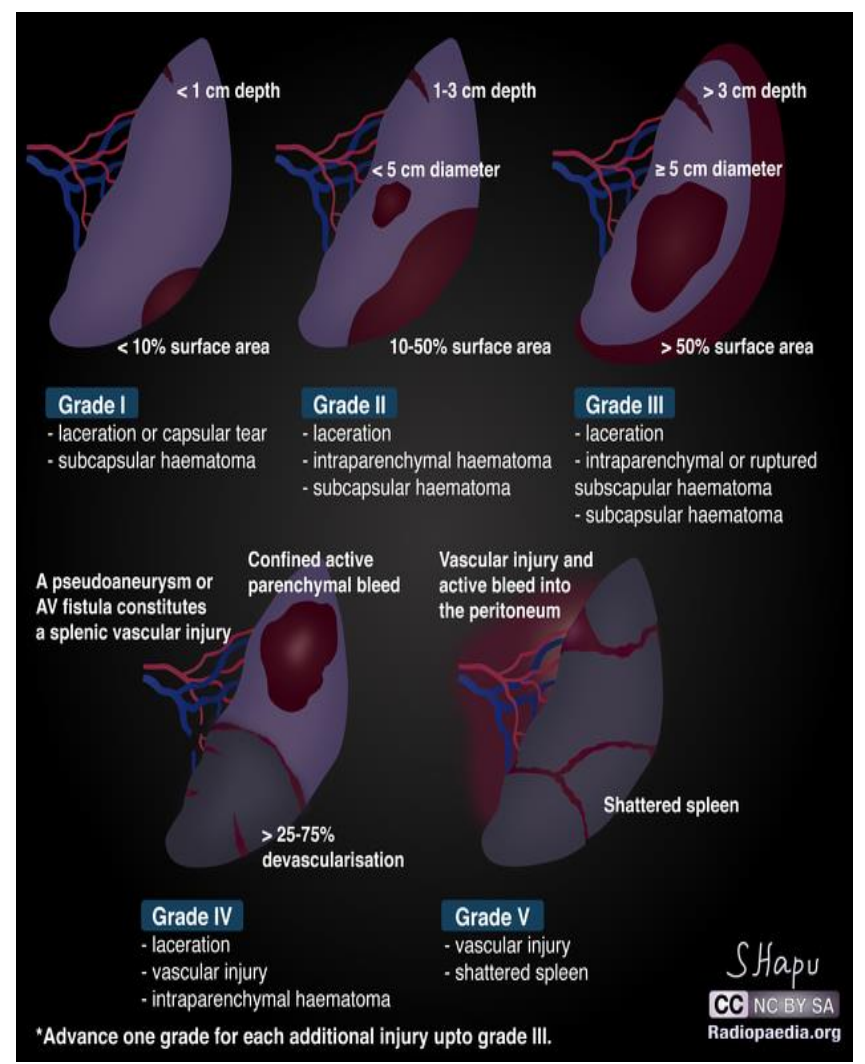

Diagram 2: Grading of Splenic injuries

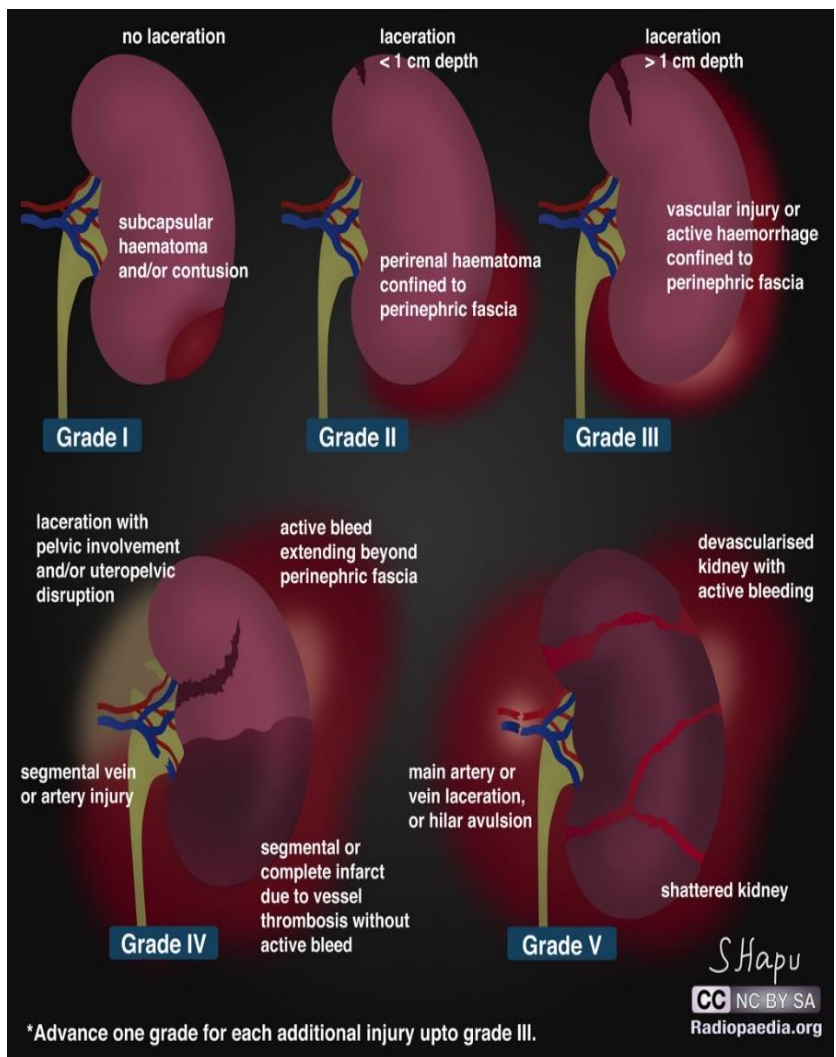

Diagram 3: Grading of Renal Injuries

\section{MATERIALS AND METHODOLOGY}

$>$ Type of study: Retrospective study

$>$ Sample Size: 50 patients

$>$ Location of study: Saveetha Medical College and Hospital, Chennai.

> Duration: 3 Months (January 2020 to March 2020)

\section{Inclusion Criteria:}

1) Patients presenting to the emergency department of the hospital with complaints of blunt trauma to the abdomen.

2) Patients with Ultrasound Abdomen proven solid organ injury.

3) Patients with CT Abdomen and pelvis proven solid organ injury.

$>$ Exclusion Criteria:

1) Any old follow up case.

2) Any patients having an associated hollow organ injury.

The study was started after obtaining consent from the Institutional Ethics Committee of Saveetha Medical College and Hospital. The data were entered into Microsoft Excel 2013 and statistical analysis was done.

\section{RESULTS}

1) Distribution of patients based on the solid organ involved:

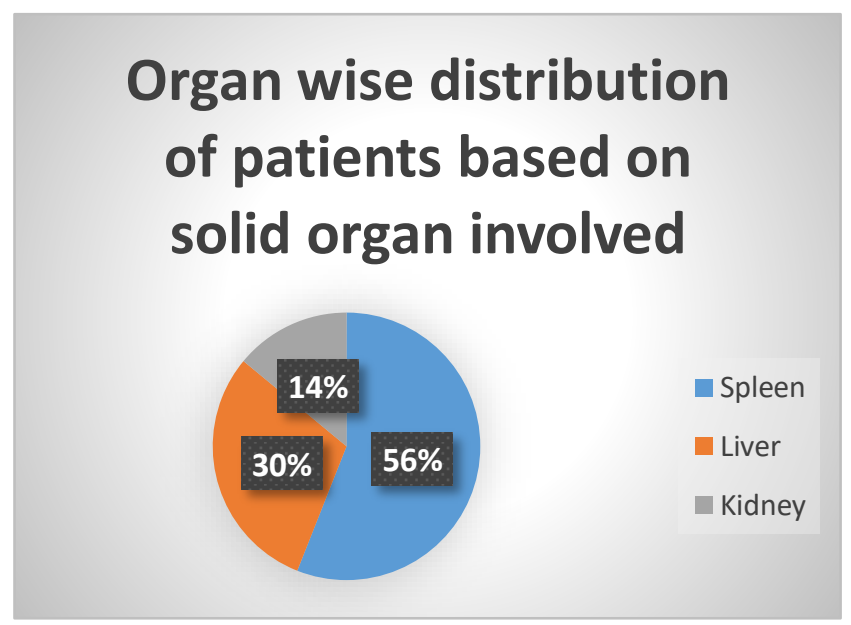

Fig 1

It is found that out of the total 50 cases, 28 patients presented with Splenic injuries, 15 patients presented with Liver injuries and 7 patients presented with Renal injuries.

2) Parameters for conservative management of Splenic injury:

Splenic injury is classified and managed according to the American Association for the Surgery of Trauma (AAST) grading of splenic injuries: 
- grade I

- subcapsular hematoma $<10 \%$ of surface area

○ parenchymal laceration $<1 \mathrm{~cm}$ depth

- capsular tear

- grade II

- subcapsular hematoma $10-50 \%$ of surface area

o intraparenchymal hematoma $<5 \mathrm{~cm}$

- parenchymal laceration $1-3 \mathrm{~cm}$ in depth

- grade III

○ subcapsular hematoma $>50 \%$ of surface area

- ruptured subcapsular or intraparenchymal hematoma $\geq 5$ $\mathrm{cm}$

- parenchymal laceration $>3 \mathrm{~cm}$ in depth

- grade IV

○ any injury in the presence of a splenic vascular injury or active bleeding confined within splenic capsule

o parenchymal laceration involving segmental or hilar vessels producing $>25 \%$ devascularisation

- grade V

○ shattered spleen

○ any injury in the presence of splenic vascular injury with active bleeding extending beyond the spleen into the peritoneum

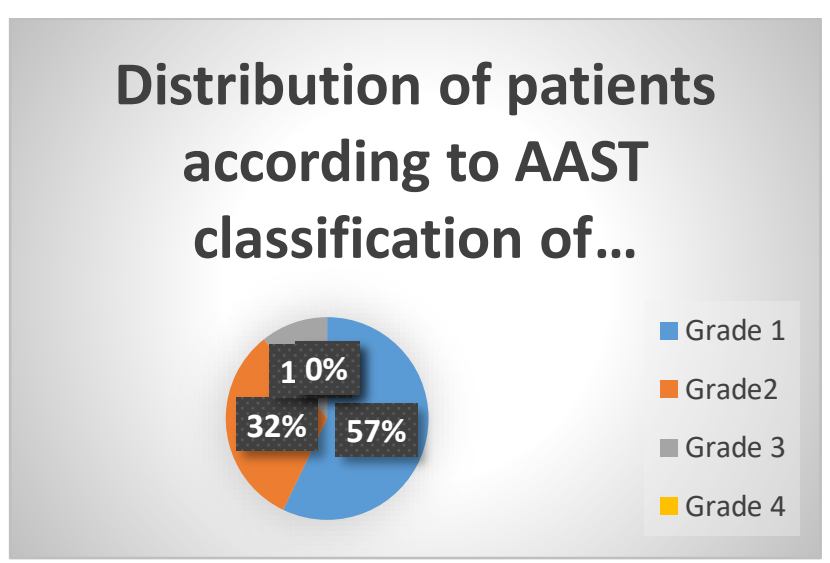

Fig 2

It is found that out of the total 28 patients who underwent conservative mode of management, 16 patients belonged to Grade I, 9 patients belonged to Grade II and 3 patients belonged to Grade III. Thus, it is observed that patients who belonged to Grade I, II and III had underwent conservative method of management.

3) Parameters for conservative management of Hepatic injury:

Hepatic injury is classified and managed according to the American Association for the Surgery of Trauma (AAST) grading of Hepatic injuries:

\section{- grade I}

○ hematoma: subcapsular, $<10 \%$ surface area

○ laceration: capsular tear, $<1 \mathrm{~cm}$ parenchymal depth

- grade II

- hematoma: subcapsular, $10-50 \%$ surface area

- hematoma: intraparenchymal $<10 \mathrm{~cm}$ diameter

- laceration: capsular tear 1-3 cm parenchymal depth, <10 cm length

\section{- grade III}

○ hematoma: subcapsular, $>50 \%$ surface area of ruptured subcapsular or parenchymal hematoma

○ hematoma: intraparenchymal $>10 \mathrm{~cm}$

- laceration: capsular tear $>3 \mathrm{~cm}$ parenchymal depth

- vascular injury with active bleeding contained within liver parenchyma

- grade IV

- laceration: parenchymal disruption involving 25-75\% hepatic lobe or involves 1-3 Couinaud segments.

- vascular injury with active bleeding breaching the liver parenchyma into the peritoneum

- grade $\mathbf{V}$

- laceration: parenchymal disruption involving $>75 \%$ of hepatic lobe

o vascular: juxtahepatic venous injuries (retrohepatic vena cava / central major hepatic veins)

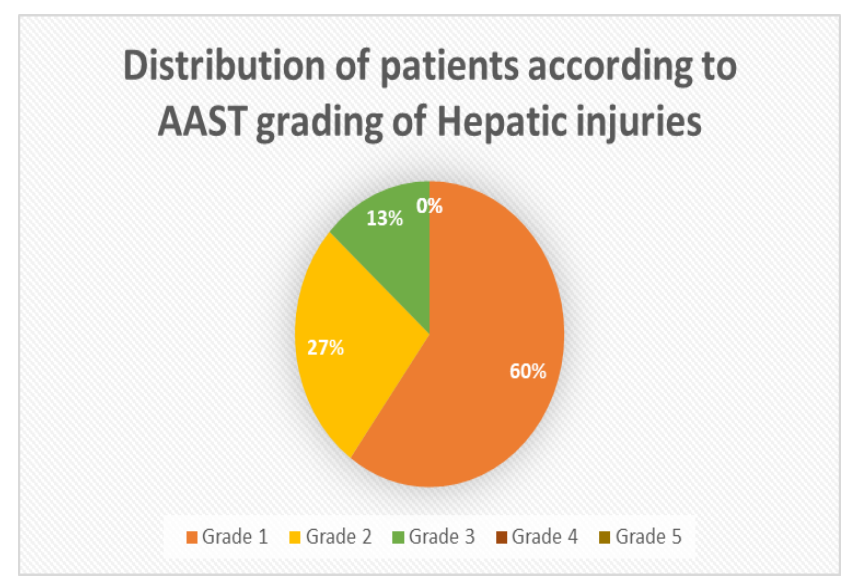

Fig 3

It is found that out of the total 15 patients who underwent conservative mode of management, 9 patients belonged to Grade I, 4 patients belonged to Grade II and 2 patients belonged to Grade III. Thus, it is observed that patients who belonged to Grade I, II and III had underwent conservative method of management.

4) Parameters for conservative management of Renal injury:

Renal injury is classified and managed according to the American Association for the Surgery of Trauma (AAST) grading of Renal injuries:

- grade I

- subcapsular hematoma or contusion, without laceration

- grade II

- superficial laceration $\leq 1 \mathrm{~cm}$ depth not involving the collecting system (no evidence of urine extravasation)

- perirenal hematoma confined within the perirenal fascia

- grade III

- laceration $>1 \mathrm{~cm}$ not involving the collecting system (no evidence of urine extravasation)

o vascular injury or active bleeding confined within the perirenal fascia

- grade IV 
- laceration involving the collecting system with urinary extravasation

- laceration of the renal pelvis and/or complete ureteropelvic disruption

- vascular injury to segmental renal artery or vein

- segmental infarctions without associated active bleeding (i.e. due to vessel thrombosis)

o active bleeding extending beyond the perirenal fascia (i.e. into the retroperitoneum or peritoneum)

- grade $\mathbf{V}$

- shattered kidney

- avulsion of renal hilum or laceration of the main renal artery or vein: devascularisation of a kidney due to hilar injury

○ devascularised kidney with active bleeding

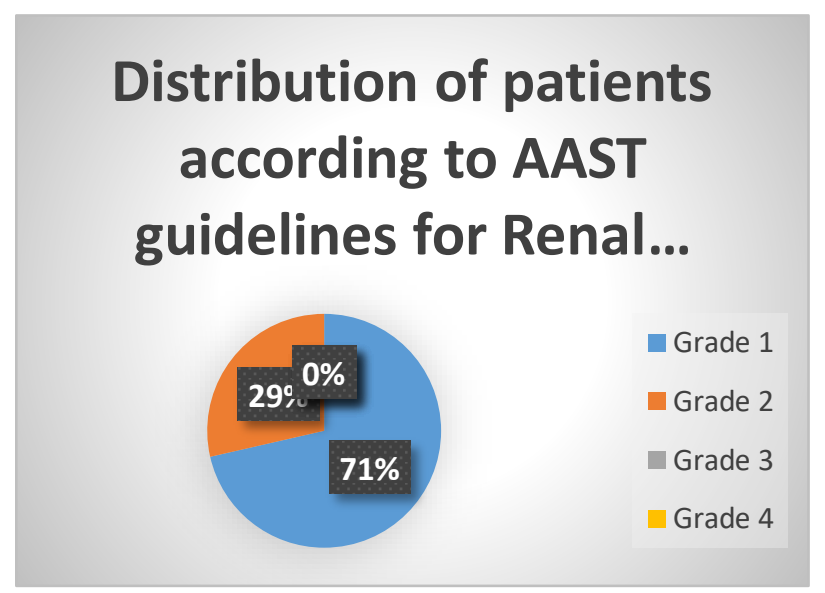

Fig 4

It is found that out of the total 7 patients who underwent conservative mode of management, 5 patients belonged to Grade I and 2 patients belonged to Grade II. Thus, it is observed that patients who belonged to Grade I and II had underwent conservative method of management.

\section{DISCUSSION}

Solid organ injuries can be caused due to multiple reasons, however, most patients commonly present with a history of any external trauma to the abdomen. Among these, patients usually present with a solid organ injury to the emergency department following a road traffic accident or any blunt trauma to the abdomen.

Management of solid organ injuries has changed drastically during the last 2 decades. While Surgical mode of management was the predominant mode of management during the early 1990 's, there has been a drastic shift from surgical management to conservative mode of management. [12] This shift from surgical to conservative has been seen especially in Hemodynamically stable patients thanks to the advent of evidence guided approach and developments in radiology.

Two main radiological tools which have helped in differentiating whether the patient requires a surgical or conservative management are Ultrasound of the abdomen and Computed Tomography of the abdomen and pelvis.
Ultrasound of the abdomen is an initial assessment which can be performed as it is safe and uses non ionizing radiation. It helps by detecting free fluid. Free fluid which is seen after a case of Trauma is assumed to be an indirect evidence of injury.

Computed Tomography is a more definitive investigation which is widely considered to be the imaging modality of choice. It is widely used, especially in hemodynamically stable patients. It is both specific as well as sensitive and further helps in grading.

In comparison with previous studies conducted on conservative management, it has been shown that Conservative mode of management of solid organs is both safe and effective, however, the radiological parameters for conservative management has not been specifically identified. Thus, this study was performed as an attempt to establish radiological parameters in order to perform conservative mode of management for patients presenting to the emergency department with either a Spleen, Liver or Kidney injury.[13][14][15]

\section{REFERENCES}

[1]. Sawhney C, Kaur M, Gupta B, Singh PM, Gupta A, Kumar S, et al. Critical care issues in solid organ injury: Review and experience in a tertiary trauma center. Saudi J Anaesth 2014;8:29-35.

[2]. Notash AY, Amoli HA, Nikandish A, Kenari AY, Jahangiri F, Khashayar P. Non-operative management in blunt splenic trauma. Emerg Med J 2008;25:210-2.

[3]. Raza M, Abbas Y, Devi V, Prasad KV, Rizk KN, Nair PP. Non operative management of abdominal trauma: a 10 years review. World J Emerg Surg 2013;8:14

[4]. Jansen JO, Yule SR, Loudon MA. Investigation of blunt abdominal trauma. BMJ. 2008;336(7650):938942. doi:10.1136/bmj.39534.686192.80

[5]. ShumanWP,Holtzman SR,Bree RL,BettmanMA, CascaniT, FoleyWD, et al. American College of Radiology appropriateness criteria. Blunt abdominal trauma

[6]. Healey M, Simons RK, Winchell RJ, Gosink BB, Casola G, Steele JT, etal.Aprospective evaluationof abdominalultrasoundin trauma:isit useful? J Trauma 1996;40:875-85

[7]. Boulanger BR, McLellan BA, Brenneman FD, Wherrett L, Rizoli SB, Culhane J, et al. Emergent abdominal sonography as a screening test in a new diagnostic algorithm for blunt trauma. J Trauma 1996;40:867-74

[8]. Rozycki GS, Ochsner MG, Jaffin JH, Champion HR. Prospective evaluation of surgeons' use of ultrasound in the evaluation of trauma patients. J Trauma 1993;34:516-27.

[9]. Rozycki GS, Ballard RB, Feliciano DV, Schmidt JA, Pennington SD. Surgeon-performed ultrasoundfor the assessment of truncal injuries: lessons learned from 1540 patients. Ann Surg 1998;228:557-67. 
[10]. Royal CollegeofRadiologists.Makingthebestuse of clinical radiology services: referral guidelines. London: RCR, 2007.

[11]. Hoff WS, Holevar M, Nagy KK, Patterson L, Young JS, Arrillaga A, et al; Eastern Association for the Surgery of Trauma. Practice management guidelines for the evaluation of blunt abdominal trauma: the EAST practice management guidelines work group. J Trauma 2002;53:602-15.

[12]. Okuş A, Sevinç B, Ay S, Arslan K, Karahan Ö, Eryilmaz MA. Conservative management of abdominal injuries. Ulus Cerrahi Derg. 2013;29(4):153-157. Published 2013 Dec 1. doi:10.5152/UCD.2013.2300

[13]. Stawicki SP. Trends in nonoperative management of traumatic injuries - A synopsis. Int J Crit Illn Inj Sci 2017;7:38-57.

[14]. Velmahos GC, Toutouzas KG, Radin R, Chan L, Demetriades D. Nonoperativemanagement of blunt injury to solid abdominal organs: a prospective study. Arch Surg 2003;138:844-51

[15]. Stein DM, Scalea TM. Nonoperative management of spleen and liver injuries. J Intensive Care Med 2006;21:296-304. 